\title{
The Effect of the Extracts of Endophytic Fungi on Pancreatic a-Amylase Activity
}

\author{
Dilorom Ruzieva ${ }^{1}$, Hasan Hasanov ${ }^{2}$, Liliya Abdulmyanova ${ }^{1}$, Gulchehra Rasulova ${ }^{1}$, Regina Sattarova ${ }^{1}$ and \\ Toshkhon Gulyamova ${ }^{1}$ \\ 1. Department of Biochemistry of Physiologically Active Compounds, Institute of Microbiology of the Academy of Sciences RU, \\ Tashkent 100128, Uzbekistan
}

2. Faculty of Technology of Foodstuff Products, Tashkent Institute of Chemical Technology, Tashkent 100011, Uzbekistan

\begin{abstract}
Inhibitors of pancreatic $\alpha$-amylase offer an effective strategy to lower the levels of postprandial hyperglycemia by control of starch breakdown. Among 86 fungal endophytes isolated from 15 medicinal plants Aspergillus terreus-AF104S, Aspergillus egypticus-HT166S and Penicillium sp.-CC200 exhibited strong pancreatic amylase inhibitory potential were selected. Endophytes were subjected to ethyl acetate extraction and tested for $\alpha$-amylase inhibition, in order to assess and evaluate their inhibitory potential on pancreatic $\alpha$-amylase. Analysis showed concentration dependent enzyme inhibition up to 83\% with half inhibition (IC50) values for less $25 \mathrm{mg} \cdot \mathrm{mL}^{-1}$, which is lower than acarbose as control. It was observed 3-fold increasing of $\mathrm{V}_{\max }$ and maintenance $\mathrm{K}_{\mathrm{m}}$ at control level in the presence of extracts A. terreus-AF104S and Penicillium sp.-CC200, while in presence of extract A. egypticus-HT166S $\mathrm{K}_{\mathrm{m}}$ was doubled, and $\mathrm{V}_{\max }$ was maintained at the control level. Kinetic studies allow proposing the competitive mode of $\alpha$-amylase inhibition by extracts A. egypticus-HT166S and uncompetitive inhibition by extracts A. terreus-AF104S and Penicillium sp.-CC200.
\end{abstract}

Key words: Endophytic fungi, medicinal plants, $\alpha$-amylase, bio-active natural products, inhibitory activity.

\section{Introduction}

Diabetes mellitus, one of the common metabolic disorders that characterized by elevated blood glucose level [1]. Postprandial hyperglycemia caused by consumption of high-carbohydrate diets can progress to full symptomatic type 2 diabetes (DM2) [2]. The control of hyperglycemia is critical in the management of diabetes mellitus since in long term, acute and chronic complications can occur with significant morbidity and mortality [1, 3]. International Diabetes Federation (IDF) has reported that 8.3\% (366 million) of the adult diabetic patients worldwide is 366 million in 2011, and it is predicted to increase to 552 million people by 2030 that can be managed by diet control and consumption of various synthetic antidiabetic

Corresponding author: Regina Sattarova, senior research fellow, research field: search and study of bioactive metabolites of microorganisms with medicinal and agricultural potential. drugs [4, 5].

Current therapeutic approach for the control of postprandial hyperglycemia, as the earliest metabolic response in DM2, is to retard and reduce the digestion and absorption of ingested carbohydrates by the inhibition of carbohydrate-hydrolyzing enzymes, such as $\alpha$-amylase and/or $\alpha$-glucosidase [6]. Commercial hypoglycemic agents as acarbose, miglitol, voglibose, metformin effectively control blood glucose by competitive and reversible inhibition of $\alpha$-amylase and $\alpha$-glycosidase from intestine as well as pancreas, and potentially reduce the progression of diabetes [7]. Despite their efficacy, these drugs are often associated with some undesirable adverse gastrointestinal side effects [6, 7]. Therefore, the management of diabetes without any side effects is still a challenge and plants continue to play an important role in the discovery of new compounds for the treatment of this disease [8, 9]. 
At the same time, the endophytic fungi asymptomatic inhabiting various tissues of living plants and producing huge number of unique bioactive substances become an alternative resource of hypoglycemic antidiabetic compounds [10]. It has been reported, the metabolites of endophytic fungi of some medicinal plants have potential as inhibitors of $\alpha$-glycosidase and $\alpha$-amylase [11]. Recenly, we have isolated a number of endophytic fungi from several local medicinal plants and the strains producing metabolite with high inhibitory activity against pancreatic amylase have been selected [12].

In this context, the aim of this work is to study the effect on the activity of pancreatic $\alpha$-amylase ethyl acetate extracts of endophytic fungi isolated from anti-diabetic plants Helianthus tuberosus, Celosia cristata and Allium filidens.

\section{Materials and Methods}

Cultivation of three selected endophytes for obtaining fungal biomass was carried out by submerge fermentation in $500 \mathrm{~mL}$ flasks with $100 \mathrm{~mL}$ Chapek-Dox medium for 5 days at $26^{\circ} \mathrm{C}$.

For extraction of inhibitory metabolites $5 \mathrm{~g}$ of homogenized biomass of each isolate was transferred to a conical flask containing $50 \mathrm{~mL}$ of ethyl acetate and left for one day on shaker at room temperature. The mixture was filtered through a paper filter (Whatman No. 1), $\mathrm{Na}_{2} \mathrm{SO}_{4}$ was added at concentration $40 \mu \mathrm{g} \cdot \mathrm{mL}^{-1}$. Extract was evaporated to dryness on a rotary evaporator, $1 \mathrm{~mL}$ of dimethyl sulfoxide (DMSO) was added and stored at $-40{ }^{\circ} \mathrm{C}$ prior to use.

Determination of $\alpha$-amylase activity was carried out by the modified method used for measurement in the plant extract [13]. Solution of starch as a substrate was prepared in concentration $1 \mathrm{~g} 10 \mathrm{~mL}^{-1}$ water, boiled for 2 minutes, adjusted to $100 \mathrm{~mL}$ with distilled water and used within 2-3 days. For the preparation of iodine reagent $0.5 \mathrm{~g}$ of crystalline iodine, $5 \mathrm{~g}$ of potassium iodide were dissolved in $250 \mathrm{~mL}$ of water; $2 \mathrm{~mL}$ of this reagent was adjusted to $100 \mathrm{~mL}$ by $0.1 \mathrm{M}$
$\mathrm{HCl}$ and used as working solution. To $2 \mathrm{~mL}$ of the prepared starch solution $100 \mu \mathrm{L}$ pancreatic $\alpha$-amylase (13 u. $\mathrm{mL}^{-1}$ in $0.1 \mathrm{M}$ Na-acetate buffer $\left.\mathrm{pH} 4.7\right), 100 \mu \mathrm{L}$ of the extract endophyte $\left(20 \mathrm{mg} \cdot \mathrm{mL}^{-1}\right), 2 \mathrm{~mL}$ of acetate buffer were added and incubated for 10 minutes at $30{ }^{\circ} \mathrm{C}$. The sample without extract used as control. After incubation the reaction was terminated by adding $10 \mathrm{~mL}$ of iodine reagent and the absorbance was measured at $630 \mathrm{~nm}$ using a spectrophotometer.

Inhibitory activity was expressed by the formula: $\left(A_{0}-A_{t}\right) / A_{0} \times 100 \%$, where $A_{0}$-absorption of control sample, $A_{t}$-the absorption of test sample, respectively.

The mode of inhibition of endophytic extracts on $\alpha$-amylase action was determined by increasing substrate (starch) concentration. Kinetic parameters, namely Michaelis-Menten constant affinity $\left(\mathrm{K}_{\mathrm{m}}\right)$ and maximum velocity $\left(\mathrm{V}_{\max }\right)$ were derived from appropriate Lineweaver-Burk plots [14].

\section{Results and Its Discussion}

The study of lipid-lowering and anti-diabetic activity of various fractions of extracts of the mycelium 17 endophytic fungi isolated from Salvadora oleoides Decne (Salvadoraceae), showed that the extracts of two endophytic fungi $p p$. Aspergillus and Phoma significantly decrease blood glucose level [15]. Positively active as inhibitors of $\alpha$-amylase and $\alpha$-glycosidase were extracts of 2 from 9 fungal endophytes isolated from the Indian anti-diabetic plants Momordica charantia and Trigonella foenum-graceum. In the experimental conditions in vitro IC50 of two isolates were lower than the control acarbose [16]. According to study of antidiabetic activity of Syncephalastrum racemosum isolated from red algae Gracilaria corticata, its acetone and methanol extracts inhibited amylase activity for 19.4 and $23.7 \%$, respectively [17].

From the roots, stems and leaves of 15 plants growing in Uzbekistan we obtained 86 endophytic fungal isolates. It was established that the ethyl acetate 
extracts of number of isolates at concentration 100 $\mu \mathrm{g} \cdot \mathrm{mL}^{-1}$ inhibited pancreatic $\alpha$-amylase activity in vitro in the range of $2.5 \%$ to $85 \%$ [12]. Among studied fungal strains as the most active there were selected Aspergillus terreus-AF104S isolated from Allium filidens, Aspergillus egypticus-HT166S from Helianthus tuberosus and Penicillium sp.-CC200 from Celosia cristata.

Studies of dose-dependent inhibitory effects of extracts revealed the highest inhibitory action caused by $100 \mathrm{mg}$ of extracts as well as acarbose, while values of IC50 of all three strains were lower than acarbose (Table 1).

In the study of inhibitory properties of various compounds according to any enzymes it is important to determine their influence on kinetic characteristics of the enzymatic process. In this regard, we have studied the dependence of the rate of amylolytic reaction on the concentration of substrate in the presence of extracts from A. terreus-AF104S, A. egypticus-HT166S and Penicillium sp.-CC200.

The rate of hydrolysis of starch in the presence of extracts on Lineweaver-Burk plot is showed in Figs. 1-3. Maximum achievable velocity of reaction (on $y$-axis) decreases in the presence of the extracts of endophytes Penicillium sp.-CC200 and A. terreus-AF104S (Figs. 1 and 2).

However, the effective value of the apparent Michaelis constant does not change (on the x-axis). As it can be seen from summary Table 2 below, the value of $\mathrm{K}_{\mathrm{m}}$ in the presence and in the absence of inhibitory connections is of $8.33 \pm 0.4 \mathrm{mg} \cdot \mathrm{mL}^{-1}$ for both extracts (Table 2).

The maximum velocity of amylases is reduced more than 3 times (the interval on the y-axis) up to $0.26 \mathrm{mg} \cdot \mathrm{min}^{-1}$ and $0.28 \mathrm{mg} \cdot \mathrm{min}^{-1}$ by extracts Penicillium

Table 1 Effect of extracts concentration on $\alpha$-amylase inhibition.

\begin{tabular}{|c|c|c|c|c|c|}
\hline \multirow[b]{2}{*}{ № } & \multirow[b]{2}{*}{ Extracts, mg } & \multicolumn{4}{|c|}{$\alpha$-amylase inhibition, $\%$} \\
\hline & & $\begin{array}{l}\text { Acarbose- } \\
\mathrm{IC}_{50}-30\end{array}$ & $\begin{array}{l}\text { A. terreu- } \\
\text { AF } 104 S-\mathrm{IC}_{50}-25\end{array}$ & $\begin{array}{l}\text { A. egypticus- } \\
\text { HT166S-IC }{ }_{50}-20\end{array}$ & $\begin{array}{l}\text { Penicillium sp.- } \\
\text { CC200- } \mathrm{IC}_{50}-25\end{array}$ \\
\hline 2 & 60 & 74.2 & 62.5 & 70.2 & 68.5 \\
\hline 3 & 100 & 82.0 & 70.5 & 82.0 & 83.0 \\
\hline 4 & 120 & 80.0 & 60.0 & 80.0 & 71.2 \\
\hline
\end{tabular}

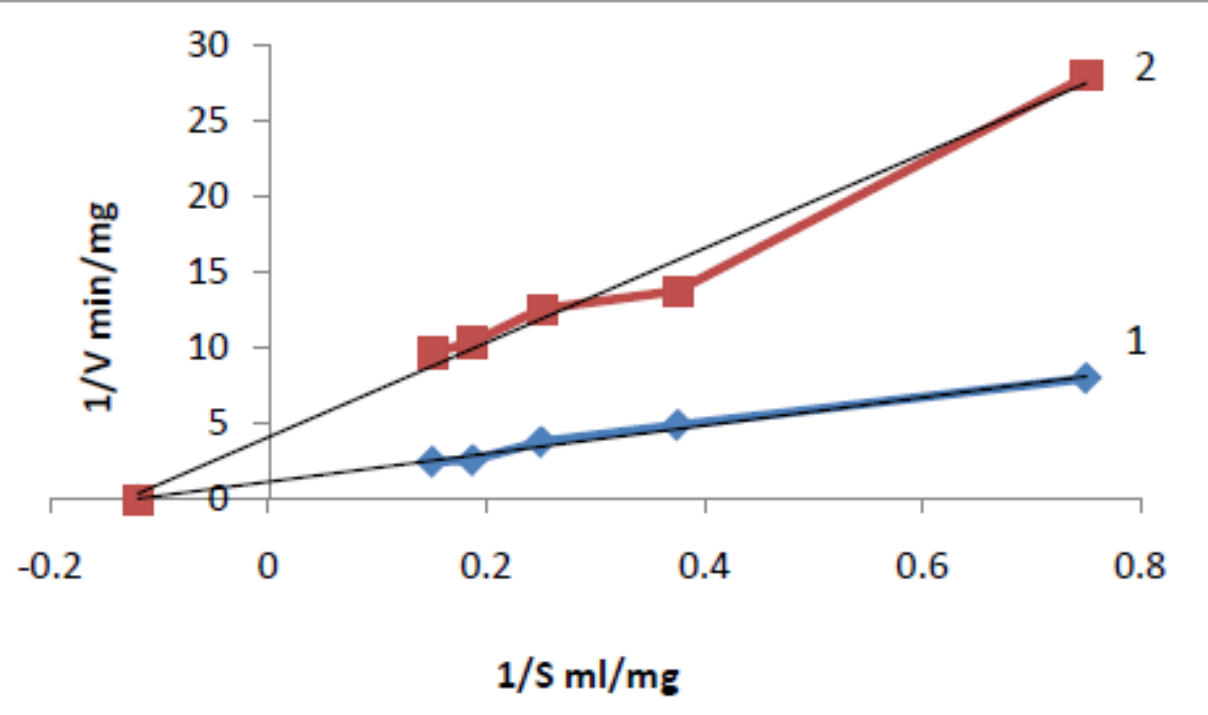

Fig. 1 The influence of Penicillium sp.-CC200 extract on activity of $\alpha$-amylase at different concentration of substrate (1-without extract, 2-with extract). 


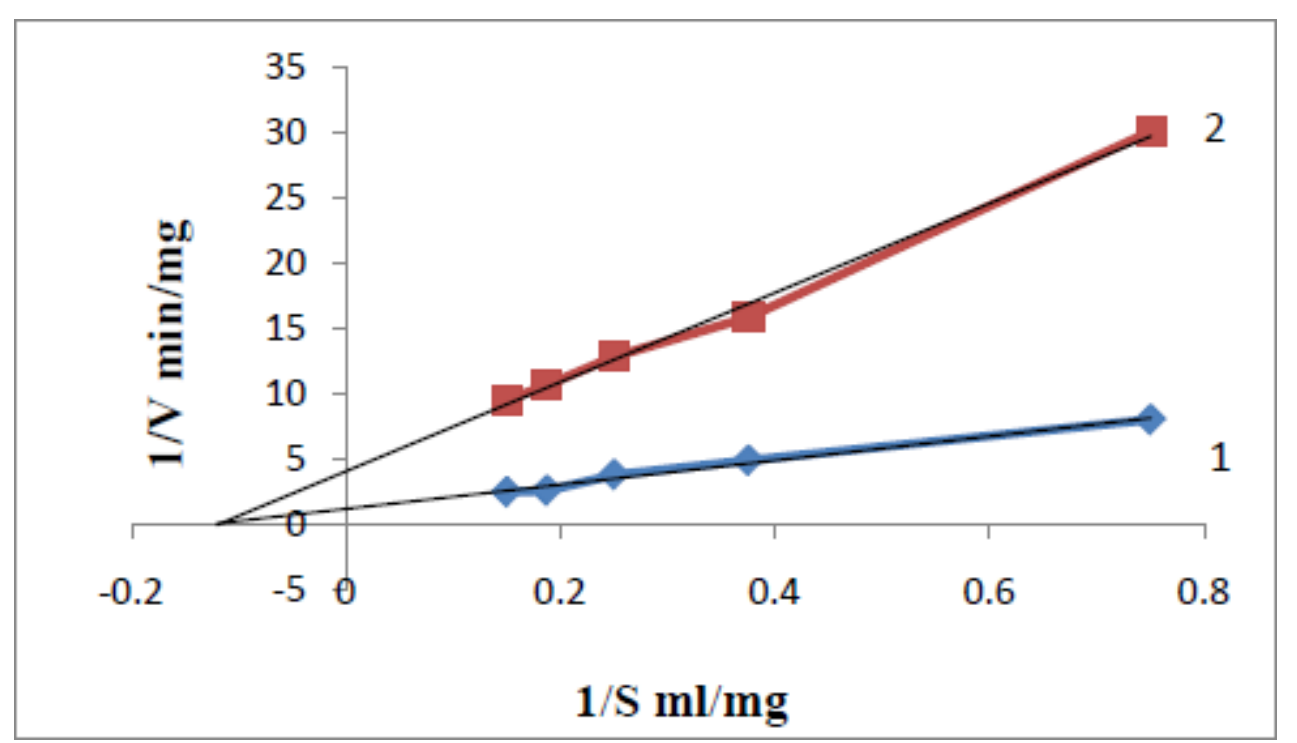

Fig. 2 The influence of $A$. terreus-AF104S extract on activity of $\alpha$-amylase at different concentration of substrate (1-without extract, 2-with extract).

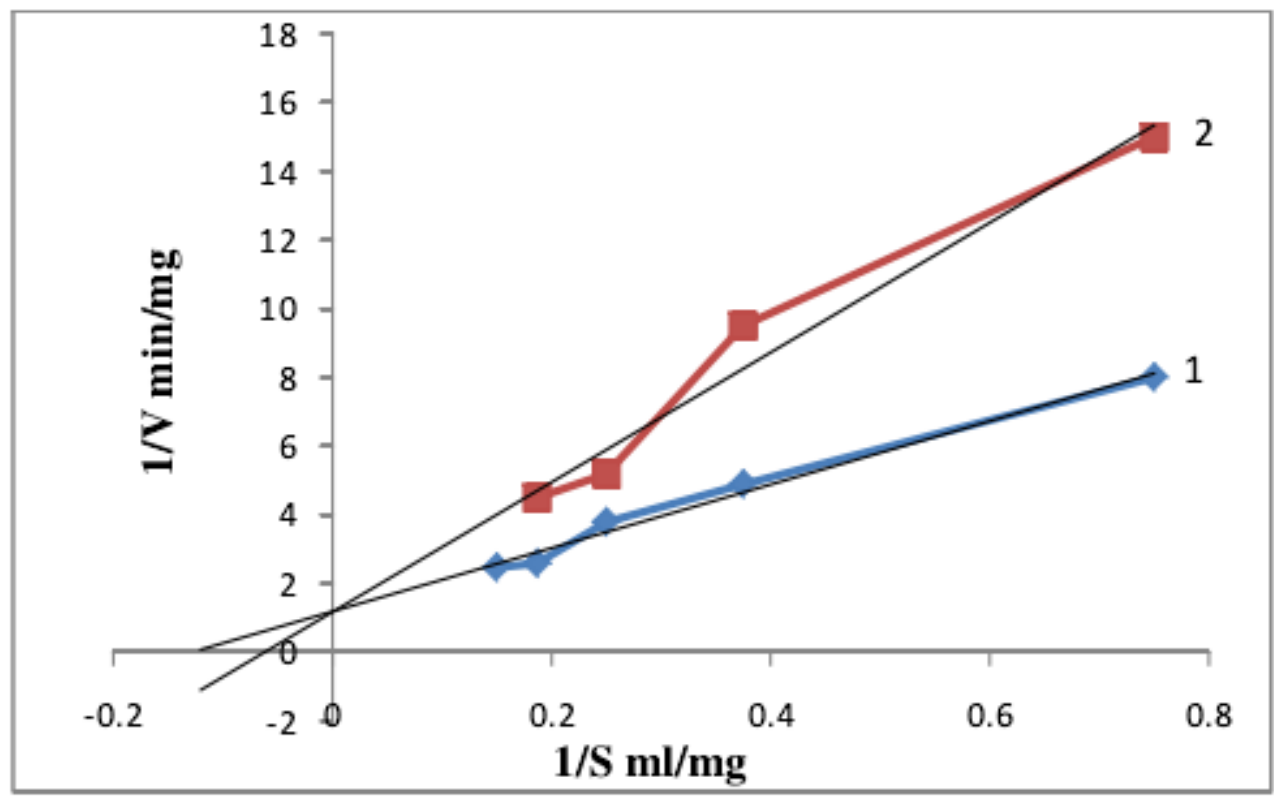

Fig. 3 The influence of A. egypticus-HT166S extract on activity of $\alpha$-amylase at different concentration of substrate (1-without extract, 2 -with extract).

Table 2 Effect of inhibitory extracts on catalytic properties of pancreatic $\alpha$-amylase.

\begin{tabular}{|c|c|c|c|c|c|c|}
\hline \multirow[b]{2}{*}{ № } & & \multirow{2}{*}{$\begin{array}{l}\text { Control } \\
\text { (without extracts) }\end{array}$} & \multicolumn{4}{|c|}{ Extracts } \\
\hline & & & $\begin{array}{l}\text { Penicillium } \\
\text { sp.-CC200 }\end{array}$ & A. terreus-AF104S & A. egypticus-HT166S & Acarbose \\
\hline 1 & $\mathrm{~K}_{\mathrm{m}}, \mathrm{mg} \cdot \mathrm{mL}^{-1}$ & $8.33 \pm 0.4$ & $8.33 \pm 0.4$ & $8.33 \pm 0.4$ & $15.8 \pm 0.6$ & $55.0 \pm 2.0$ \\
\hline 2 & $\mathrm{~V}_{\max }, \mathrm{mg} \min ^{-1}$ & $0.9 \pm 0.05$ & $0.26 \pm 0.02$ & $0.28 \pm 0.02$ & $0.9 \pm 0.05$ & $0.9 \pm 0.05$ \\
\hline
\end{tabular}




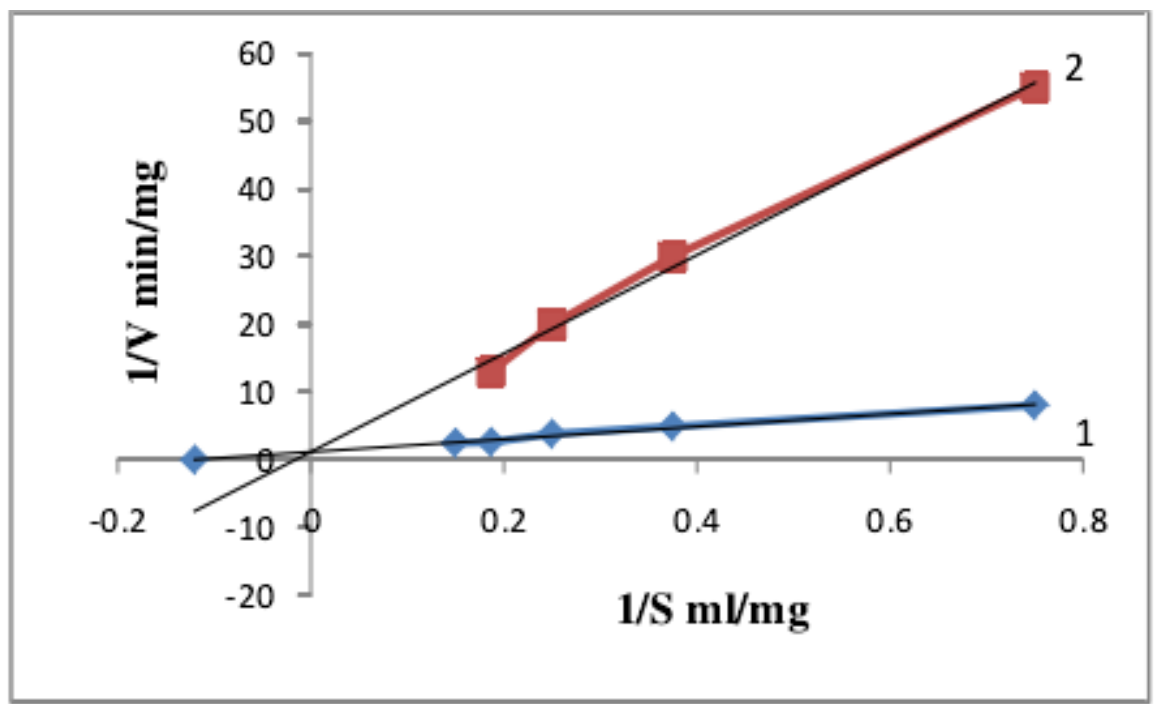

Fig. 4 The influence of acarbose on $\alpha$-amylase activity at different concentration of substrate (1-without acarbose, 2 -with acarbose).

sp.-CC200 and A. terreus-AF104S, respectively. In the absence of inhibitory substances maximum velocity of hydrolysis is $0.9 \pm 0.05 \mathrm{mg} \cdot \mathrm{min}^{-1}$. This tends to suggest an uncompetitive mode of action. Uncompetitive inhibitors bind to enzyme-substrate complex forming an enzyme-substrate-inhibitor complex and delays rate of reaction [18].

As it can be seen from the data presented in Fig. 3, despite a decrease in the activity of amylase, the extract of A. egypticus-HT166S had no effect on the value of amylase catalytic constants in the presence of inhibitory compounds, the value of Michaelis constant is increased by 2 times and is $15.8 \pm 0.6 \mathrm{mg} \cdot \mathrm{mL}^{-1}$ (Table 2). This suggests that the type of inhibition is competitive, i.e. the affinity of the inhibitor to the enzyme is higher than that of starch.

A noticeable change in the kinetic constants for amylase was observed with the commercial inhibitor acarbose (Fig. 4). As it can be seen from the obtained data, despite the decrease of amylase activity, acarbose does not affect the value of the catalytic constants. Michaelis constant is increased almost by 7 times and is $55.0 \pm 2.0 \mathrm{mg} \cdot \mathrm{mL}^{-1}$ (axis of abscissa). This suggests that the affinity of the inhibitor to the enzyme is higher than that of starch, and the inhibition of the activity occurs at very competitive type.

It should be noted that kinetic characteristics of inhibitory action by Lineweaver-Burk coordinates for endophytic inhibitors poorly studied, while several scientific reports highlight the inhibitory action on $\alpha$-amylase of plant phytochemicals [19, 20]. For example, traditionally used antidiabetic medicinal plants of Mauritius were studied for amylases kinetics in vitro. In particular, it was found that in the presence of methanol extracts of two plants (Elaeodendron orientale and Antidesma madagascariensis) decrease in both $\mathrm{K}_{\mathrm{m}}$ and the velocity $\mathrm{V}_{\max }$ were observed. This tends to suggest an uncompetitive mode of inhibition. In contrast, methanol extracts of Erythroxylum laurifolium was found to follow mixed type of inhibition. Mixed inhibitor bind to free and to substrate bound enzyme and interfere with binding and catalysis of substrate, increasing affinity and decreasing reaction rate [18].

There is also report about influence on $\alpha$-amylases kinetics of Syncephalastrum sp. isolated from medicinal plant Adathoda beddomei. It was shown that crude extract of mycelium inhibited $\alpha$-amylase activity for $72.5 \%$. Mode of inhibition of mycelial crude extract on amylase activity was determined by means Lineweaver-Burk plot analysis of data according Michaelis-Menten kinetics and appeared to be competitive $\left(K_{m}\right.$ increases whereas $V_{\max }$ remains the same [21]. 


\section{Conclusion}

Thus, the presented data demonstrated that studied extracts of Penicillium sp.-CC200, A. egypticus-HT166S and $A$. terreus-AF104S isolated from anti-diabetic plants Helianthus tuberosus, Celosia cristata and Allium filidens are active $\alpha$-amylase inhibitors with uncompetitive and competitive modes of action. Pertaining to the role of $\alpha$-amylase in the control of postprandial hyperglycemia, selected endophytes could be alternative source for application in development of new antidiabetic strategies.

\section{References}

[1] Skyler, J. S. 2004. "Diabetes Mellitus: Pathogenesis and Treatment Strategies.” J. Med. Chem 47: 4113-7.

[2] Powers A. C., and D'alessio, D. 2011. Endocrine Pancreas and Pharmacotherapy of Diabetes Mellitus and Hypoglycemia. Goodman \& Gillman's the Pharmacological Basis of Therapeutics. 12th ed. McGraw Hill, 1237-73.

[3] El-Kaissi, S., and Sherbeeni, S. 2011. "Pharmacological Management of Type 2 Diabetes Mellitus: An Update.” Current Diabetes Reviews 7 (6): 392-405.

[4] World Health Organization (WHO). 2006. Diabetes Programme. http//www.who.Int/diabetes/en/.

[5] Federation ID. IDF diabetes atlas: International Diabetes Federation, Executive Office (2011).

[6] Raptis, S. A., and Dimitriadis, G. D. 2002. "Oral Hypoglycemic Agents: Insulin Secretagogues, Alpha-Glucosidase Inhibitors and Insulin Sensitizers.” Exp. Clin. Endocrinol Diabetes 109 (Suppl 2): S265-87.

[7] Inzucchi, S. E. 2002. "Oral Antihyperglycemic Therapy for Type 2 Diabetes.” JAMA 287: 360-72.

[8] Tundis, R., Loizzo, M., and Menichini, F. 2010. "Natural Products as $\alpha$-Amylase and $\alpha$-Glucosidase Inhibitors and Their Hypoglycaemic Potential in the Treatment of Diabetes: An Update." Mini Reviews in Medicinal Chemistry 10 (4): 315-31.

[9] Adisakwattana, S., Ruengsamran, T., Kampa, P., and Sompong, W. "In vitro Inhibitory Effects of Plant-Based Foods and Their Combinations on Intestinal $\alpha$-Glucosidase and Pancreatic $\alpha$-Amylase." BMC Complementary and Alternative Medicine 12: 110.

[10] Padhi, L., Mohanda, Y. K., and Panda, S. K. 2013. “Endophytic Fungi with Great Promises: A Review.” J. Adv. Pharm. Edu. \& Res. 3 (3): 152-70.

[11] Edward, J., and Dompeipen, Y. S. 2011. "Wahyudi Priyono Suharso, Herry Cahyana and Partomuan
Simanjuntak, Potential Endophytic Microbes Selection for Antidiabetic Bioactive Compounds Production.” Asian Journal of Biochemistry 6: 465-71.

[12] Ruzieva, D. M., Abdulmyanova, L. I., Fayzieva, F. K., Rasulova, G. A., Mahkamova, M. P., and Gulyamova, T. G. 2016. "Endofitnie Gribi Helianthus tuberosus-Ingibitori $\alpha$-Amylasi.” Journal teoreticheskoi i klinicheskoi medicini, Tashkent 3: 62-6.

[13] Picot, C. M. N., Subratty, A. H., and Mahomoodally, M. F. 2014. Inhibitory Potential of Five Traditionally Used Native Antidiabetic Medicinal Plants on $\alpha$-Amylase, $\alpha$ -Glucosidase, Glucose Entrapment, and Amylolysis Kinetics In Vitro. Hindawi Publishing Corporation Advances in Pharmacological Sciences. Article ID 739834, 7 pages.

[14] Berezin, I. V., and Klesov, A. A. 1976. "Prakticheskii kurs himicheskoi i fermentativnoy kinetiki.” Izd-vo MGU, 77-110.

[15] Dhankhar, S., Dhankhar, S., and Yadav, J. P. 2013. "Investigations towards New Antidiabetic Drugs from fungal Endophytes Associated with Salvadora oleoides Decne." Med. Chem. 9 (4): 624-9.

[16] Pavithra, N., Sathish, L., Babu, N., Venkatarathanamma, V., Pushpalatha, H., Reddy, G. B., and Ananda, K. 2014. "Evaluation of $\alpha$-Amylase, $\alpha$-Glucosidase and Aldose Reductase Inhibitors in Ethyl Acetate Extracts of Endophytic Fungi Isolated from Antidiabetic Medicinal Plants.” International Journal of Pharmaceutical Sciences and Research 5 (12): 5334-41.

[17] Ushasri, R., and Anusha, R. 2015. "In vitro Anti-diabetic Activity of Ethanolic and Acetone Extracts of Endophytic Fungi Syncephalastrum racemosum Isolated from the Seaweed Gracilaria corticata by $\alpha$-Amylase Inhibition Assay Method.” Int. J. Curr. Microbiol. App. Sci. 4 (1): 254-9.

[18] Cornish-Bowden, A. 2013. Fundamentals of Enzyme Kinetics. UK London: John Wiley \& Sons.

[19] Sama, K., Murugesan, K., and Siravaj, R. 2010. "In vitro $\alpha$-Amylase and $\alpha$-Glucosidase Inhibition Activity of Crude Ethanol Extract of Cissus arnottiana." Asian J. Plant Sci. Res. 2 (4): 550-3.

[20] McEwan, R., Madihva, R. P., Djarova, T., Oyedeji, O. A., and Opoku, A. R. 2010. " $\alpha$-Amylase Inhibitor of Amadumbe (Colocasia esculenta): Isolation, Purification and Selectivity towards $\alpha$-Amylases from Various Sources.” Afr. J. Biochem. Res. 4 (9): 220-4.

[21] Pravabathy. D., and Valli Nachiyar, C. 2013. "Antimicrobial and antidiabetic activity of endophytic fungi isolated from Adhatoda beddomei." Int. J. Pharm Phar. Sci. 5 (3): 780-3. 